\section{HERPES ZOSTER AFTER IRRADIATION} BY

FRANK ELLIS, M.D., M.Sc., F.F.R. Medical Director, Radiotherapy Department, London Hospital AND

BASIL A. STOLL, M.R.C.S., D.M.R.T.\&D., D.T.M.\&H. Chief Assistant, Radiotherapy Department, London Hospital

Since 1935 one of us (F. E.) has been of the opinion that clinically typical zoster occurring in patients who had received radiotherapy probably resulted from the treatment. The numerical incidence of zoster generally in the population is not known, so that statistically the point is difficult to prove; we believe, however, that there is presumptive evidence of such correlation.

Although the virus nature of zoster is now accepted, there is still a considerable difference of opinion on the importance of various factors predisposing to attack by the virus. Apart from the idiopathic type of disease occurring especially in adults, the infection may also arise after contact with a case of varicella, during the course of acute or chronic infections-e.g., influenza, pneumonia, or tabes - as a result of trauma to the skin (Klauder, 1947) or injury to the spine, and following poisoning by certain drugs - e.g., arsenic, mercury, or benzol. In addition, there is some association between zoster on the one hand and various forms of reticulosis and cancer, and possibly radiotherapy, on the other. The discussion and analysis of cases which follow are an attempt to clarify this latter connexion.

\section{Pathology of Zoster}

In 1900 Head and Campbell carried out pathological examination of the nervous system at necropsy on 19 patients with zoster who died in an institution within 7 to 390 days of the appearance of the eruption. In all cases a lesion was found in the posterior spinal root ganglion corresponding to the skin area involved. In all cases of zoster of the face, either the Gasserian ganglion of the fifth nerve or the geniculate ganglion of the seventh nerve was involved. Wohlwill (1924), however, in a pathological examination of six cases of idiopathic zoster, and in four cases of secondary zoster, somewhat modified the classical conception. He demonstrated that, although involvement of the posterior root ganglion is the common lesion, in some cases the posterior root itself, the posterior horn, or the anterior branch of an intercostal nerve might alone be involved as a cause of the zoster. He thus suggested that the eruption might result from involvement of any part of the afferent portion of the reflex arc without specific involvement of the posterior root ganglion.

With reference to the evidence that the virus of varicella and that of zoster are probably identical, and bearing on the ensuing discussion, Sequeira et al. (1947) quote an interesting suggestion. They postulate that during an attack of chicken-pox the virus spreads throughout the body and possibly settles in the central nervous system. It lies dormant there, but may be aroused to activity by various factors, including trauma, infection, and drugs. Such a hypothesis would link together all the following factors.

\section{Reticulosis and Zoster}

Many pathological observations have been made on the development of zoster during the course of Hodgkin's disease, lymphosarcoma, and leukaemia (especially of the lymphatic type).
With regard to clinical observations, Craver and Haagensen (1932) quote seven cases in which zoster developed out of 329 cases of reticulosis treated. In five of the seven cases the zoster was preceded by exacerbation of the glandular or splenic enlargement in the neighbourhood of the ganglion involved. None of the cases showed clinical involvement of the spine by the reticulosis. These authors thus suggest the possibility that infiltration of the ganglia by the reticulosis leads to a sensitization of the nerve cells to the zoster virus. Irradiation is not suggested as a possible cause..

Halle (1930) assessed 16 cases from the literature of zoster occurring during leukaemia, and Pancoast and Pendergrass (1924) describe four cases of zoster occurring during Hodgkin's disease. The frequency of zoster in Hodgkin's disease has been variously described as $13.4 \%$ in a series of 46 cases (Baldridge and Awe, 1930) and as low as $0.64 \%$ in a series of 156 cases (Epstein and McEachern, 1937). By adding together all reported series where zoster was noted, a total of 15 cases of zoster are reported in 576 cases of Hodgkin's disease, a proportion of less than $3 \%$. In lymphosarcoma and leukaemia the average incidence of zoster is less than $1 \%$ in a large group of cases. The variation in these figures has no definite significance, since varying numbers of cases developing zoster would be missed in each series.

\section{Cancer and Zoster}

The literature has fewer references to the association between cancer and zoster. A classical instance was noted by Charcot and Cotard (1865), who reported a case of cervical zoster associated with the presence of spinal metastases from a carcinoma of the breast. Pancoast and Pendergrass (1924) quote a case of carcinoma of the ovary with multiple metastases in which D11-L1 roots were involved by zoster. Wohlwill (1924) mentions a case of carcinoma of the stomach with involvement by carcinoma of the intercostal nerve and herpetiform eruption in the skin area supplied by that nerve. Carrière (1895) mentions a case in which zoster developed in the skin of the thigh in a case of carcinoma of the cervix uteri. Neuritis of the femoro-cutaneous nerve without infiltration by the neoplasm was shown at necropsy, and Carrière attributes the neuritis to the local action of cancer toxins. Head and Campbell (1900) and Hall (1923) mention the connexion between cancer and zoster.

The development of zoster may be the preliminary sign of the development of a tumour. Kamman (1928) describes a case of zoster of the sixth intercostal nerve which was the first sign of the development of an intradural cyst at the level of the sixth dorsal segment.

Pendergrass and Kirsh (1948), in an analysis of the results of irradiation in carcinoma of the breast, quote 16 cases of zoster in 406 patients with carcinoma mammae -a proportion of $4 \%$. Of the 16 cases, 14 had received irradiation and 15 had zoster of the thoracic region (an interesting observation in view of the thoracic location of the primary growth). In 12 of the cases there was evidence of metastases before or after the appearance of the cutaneous disease (suggesting the possibility of involvement of the spinal ganglion by the disease), but, on the other hand, four of the patients survived for 4 to 12 years after the zoster with no signs of metastases. No hypothesis regarding the association of the zoster is hazarded.

Paracchi and Pricolo (1943) quote four cases of zoster developing in the course of carcinoma and one in the course of Hodgkin's disease. In three cases of uterine cancer the zoster involved the lumbar root area. The authors state that in all cases the herpetic eruption was on 
the same side and in the same region as the spread of the tumour. All the cases had received irradiation. The follow-up in these cases is not reported, but the authors suggest that the development of zoster may be a preliminary to spread of the disease. Irradiation is not considered as a possible cause.

\section{$X$ Rays and Zoster}

In most of the cases of zoster associated with reticulosis or with cancer previously referred to in this paper the patients had received irradiation treatment. Schreus (1926) reports a case of zoster arising within 40 days of irradiation of the neck for enlarged glands, and suggests that the effect of irradiation, resu'ting as it does in hyperaemia, may decrease the resistance of the root ganglia to infection with the virus or that a slumbering infection in the ganglia may be awakened. It is possible, however, that the effect of $x$ rays on the skin may lead to zoster, as suggested by Klauder (1947) for mechanical injuries.

The implication of irradiation as an aetiological factor in the development of zoster may be deduced from the facts previously mentioned from Craver and Haagensen, Pendergrass, and Paracchi and Pricolo, although the authors did not accept this possibility.

With reference to the effect of irradiation upon the nerve tissue the observations of Mogilnitzky and Podljaschuk $(1929,1930)$ are important. They note that after irradiation of the brain of adult experimental animals by fractionated doses of $x$ rays, substances such as trypan blue and saccharated ferrous oxide are able to pass from the blood into the brain tissue. This does not occur without irradiation, and the authors conclude that there is a breakdown the region. The lesion is considered to have developed as a result of irradiation damage to the anterior horn cells, and the latent period of three to five months between completing irradiation and the development of the neuropathy suggests that the effect is not directly upon the nerve tissue but follows vascular deficiency and gliosis. The dose in the region was about 5,000 r.

This latent period of three to five months is almost exactly that which forms the peak incidence of the latent period between irradiation and zoster noted in our series of cases, thus suggesting that gliosis or late fibrosis may be associated with the development of zoster. It is of interest, however, that, in spite of the serious damage to the motor system, zoster did not develop, suggesting that some additional factor-e.g., an immunological factormay be necessary for zoster to follow irradiation.

\section{Analysis of Cases}

The number of cases considered is 45 , all developing zoster after previous irradiation. (A further 20-25 cases. have been noted, but their records have been lost.) Of the total, 39 cases are of malignant disease (including 24 cases of carcinoma of the breast) and six of non-malignant disease.

\section{Carcinoma of the Breast}

This group of 24 cases provides the main and most instructive part of the study because of its homogeneity. It includes two subgroups :

1. This consisted of 12 cases treated with radical mastectomy followed by post-operative deep $x$ rays in all cases (Table $\mathrm{I}$ ). In this group zoster developed some months after the prophy-

TABLE I.-Carcinoma of Breast--Subgroup 1. Twelve Cases of Carcinoma of Breast Treated by Radical Mastectomy and Prophylactic Irradiation

\begin{tabular}{|c|c|c|c|c|c|c|c|c|c|c|}
\hline & No. & & Age & Sex & Side of Neoplasm & Site of Zoster & Relationship & Interval & Follow-up after Zoster & Diagnosis \\
\hline $\begin{array}{ll}\text { A } & 304 \\
\text { A } & 1077 \\
\text { C } 75 \\
\text { C } 618 \\
\text { C } 620 \\
\text { C } 690 \\
\text { C } 781 \\
\text { C } 1135 \\
\text { A } 20 \\
\text { B } 378 \\
\text { B } 624 \\
\text { B } 1162\end{array}$ & $\begin{array}{l}\cdots \\
\cdots \\
\cdots \\
\cdots \\
\cdots \\
\cdots \\
\cdots \\
\cdots \\
\cdots \\
\cdots\end{array}$ & $\begin{array}{l}\cdots \\
\cdots \\
\cdots \\
\cdots \\
\cdots \\
\cdots \\
\cdots \\
\cdots \\
\cdots \\
\cdots\end{array}$ & $\begin{array}{l}50 \\
61 \\
44 \\
49 \\
62 \\
73 \\
58 \\
51 \\
64 \\
59 \\
69 \\
47\end{array}$ & $\begin{array}{l}F \\
F \\
F \\
F \\
F \\
F \\
F \\
F \\
F \\
F \\
F \\
F\end{array}$ & $\begin{array}{l}\text { Right } \\
\text { Lët } \\
\text { Right } \\
\text { Left } \\
\text { Right } \\
\text { Left } \\
\text { Right } \\
\text { ", } \\
\text { " }\end{array}$ & $\begin{array}{l}\text { Right C } \\
\text { Left D4 } \\
\text { Left D6 } \\
\text { ? } \\
\text { Right D11, 12 } \\
\text { Left C3, 4 } \\
\text { Right D2 } \\
\text { Left D4 } \\
\text { Left D (upper) } \\
\text { Right D (upper) } \\
\text { Right C1-3 } \\
\text { Left D10, 11 }\end{array}$ & $\begin{array}{l}\text { Ipsilateral } \\
\text { Contralateral } \\
\text { Ipsilateral } \\
? \\
\text { Ipsilateral } \\
\text { Contralateral } \\
\text { Ipsilateral } \\
\text { ", } \\
\text { Contralateral }\end{array}$ & $\begin{array}{r}13 / 12 \\
3 / 12 \\
10 / 12 \\
9 / 12 \\
8 / 12 \\
13 / 12 \\
6 / 12 \\
3 / 12 \\
3 / 12 \\
4 / 12 \\
12 / 12 \\
16 / 12\end{array}$ & $\begin{array}{l}\text { NSR } 25 / 12 \\
\text { NSR } 30 / 12 \\
\text { No F.U. } \\
\text { No F.U. } \\
\text { NSR } 9 / 12 \\
\text { NSR } 7 / 12 \\
\text { NSR } 11 / 12 \\
\text { NSR } 9 / 12 \\
\text { Died } 11 / 12 \text { Met. liver } \\
26 / 12 \text { Met. femur } \\
\text { NSR } 16 / 12 \\
\text { NSR } 10 / 12\end{array}$ & $\begin{array}{c}\text { Histological } \\
\text { Clinical } \\
\text { Histological } \\
\text {," } \\
\text { ", } \\
\text { Clinical } \\
\text { Histological } \\
\text { ", } \\
\text { ", }\end{array}$ \\
\hline
\end{tabular}

NSR $=$ No signs of recurrence. No F.U. $=$ No follow-up.

of the haemato-encephalic barrier-the protective barrier of the brain against toxins and other poisons circulating in the blood. This experimental work supports the hypothesis of Schreus (1926).

Most reports on the effect of $x$ rays on nervous tissue are based on animal experiments, but the general results of observation suggest to Warren (1943) that the direct effect of irradiation on the brain and spinal cord is very slight (nerve tissue being resistant), but the secondary effects-namely, endarteritis and thrombosis-may lead to complications. In fact, Janzen and Warren (1942), delivering up to $10,000 \mathrm{r}$ of $200 \mathrm{kV} x$ rays, showed as a result no pathological change in the peripheral nerves of rats.

An interesting observation is made by Greenfield and Stark (1948), who describe three cases of post-irradiation neuropathy occurring among 180 cases of seminoma testis treated post-operatively to the retroperitoneal region by 1 -million-volt $x$ rays. The patients deve'oped a flaccid paralysis of the legs without associated sensory lesions, and there was no evidence of metastatic involvement of lactic course of irradiation, there being no signs of recurrence of the disease. The group is thus a uniform series treated by a uniform surgical technique followed at an interval of two to four months by a uniform course of irradiation. In the absence of clinical signs of malignancy at the time of zoster, and accepting the evidence of the case histories that zoster was not a premonitory sign of spread of malignancy, then the neoplastic process cannot be incriminated in the development of the zoster in this group of cases. The clinical evidence, however, tends to incriminate the course of irradiation, as is seen later. In this respect it must be noted that the area treated includes the skin of the chest wall affected (and also the medial part of the contralateral chest wall), together with the supraclavicular and axillary gland areas. It is of interest that, with the technique used, areas of the skin supplied by roots C3-D8 (approximately) are irradiated. The upper dorsal vertebrae at the level D1-3 (approximately) are included at the edge of the field of irradiation and in some cases the spinal roots on both sides in this region may be irradiated (see Fig. 1). Of the 12 cases, 10 were histologically proved carcinoma, and in two the evidence was clinical only.

2. This subgroup comprised 12 cases which were treated by various methods primarily and in which different techniques of 
irradiation were practised when metastases or recurrences were clinically evident or suspected (Table II). This is a much less uniform group than the previous one, but is analysed for its confirmatory relation to the other group. The presence of active neoplasm at the time of the irradiation (and possibly at

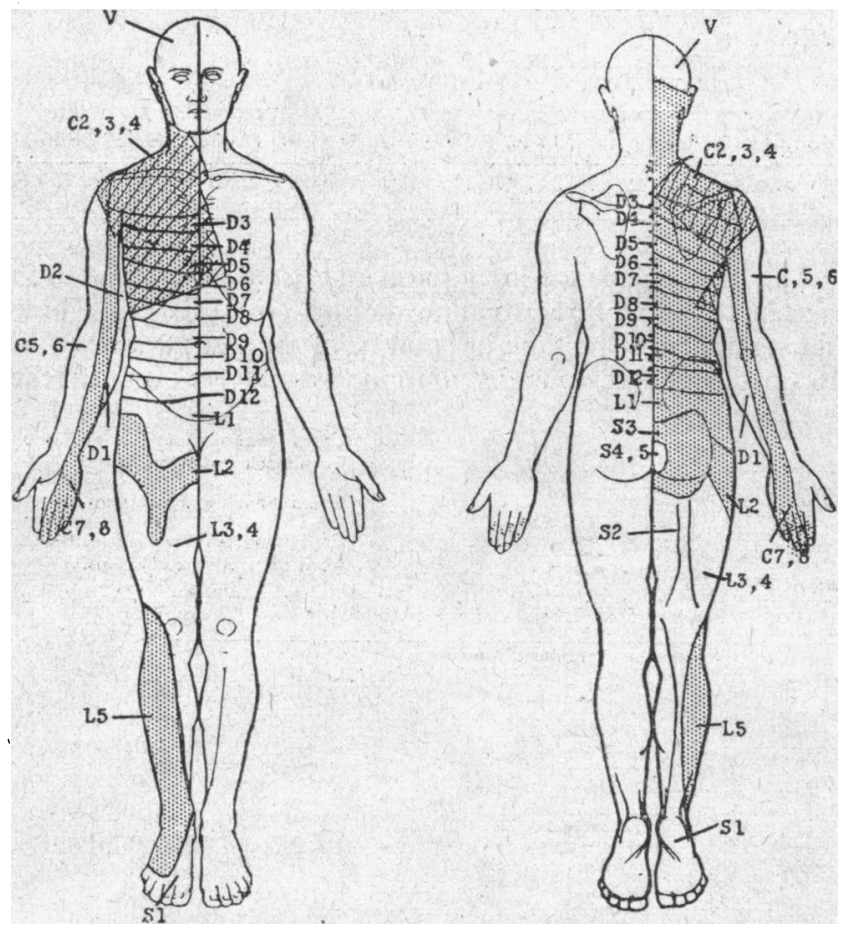

FIG. 1.-The cutaneous areas supplied by the pos:erior nerve roots; showing skin areas irradiated in standard breast technique.

the time of the zoster) is an additional factor that may be involved in the development of zoster. Of the 12 cases in this group 10 were proved either histologically or at the death of the patient, and two were established clinically.

The analysis is carried out under four headings for the group as a whole.
I. Site.-The following table shows the site involved. In each subgroup separately and for both together the upper dorsal region shows the peak incidence for zoster, and in fact represents the majority of all the cases. In

\begin{tabular}{|c|c|c|c|c|c|c|c|}
\hline & $\begin{array}{l}\text { Fifth } \\
\text { Nervo }\end{array}$ & Cervical & $\begin{array}{l}\text { Upper } \\
\text { Dorsal }\end{array}$ & $\begin{array}{l}\text { Lower } \\
\text { Dorsal }\end{array}$ & Lumbar & $\begin{array}{c}\text { Not } \\
\text { Specified }\end{array}$ & Total \\
\hline $\begin{array}{r}\text { Subgroup } 1 \\
\quad \because \quad 2 \\
\end{array}$ & $\overline{1}$ & $\begin{array}{l}3 \\
1 \\
\end{array}$ & $\begin{array}{l}6 \\
7\end{array}$ & $\begin{array}{l}2 \\
1\end{array}$ & $=$ & $\frac{1}{2}$ & $\begin{array}{l}12 \\
12\end{array}$ \\
\hline Total & 1 & 4 & 13 & 3 & - & 3 & 24 \\
\hline
\end{tabular}

idiopathic zoster the dorsal region generally shows a greater involvement than any other site. In our group of cases, however, the large preponderance of the upper dorsal site (and also the cervical site) suggests a relationship between the zoster and the site involved by the malignant disease and treated by surgery or irradiation. In Pendergrass's series of zoster in carcinoma mammae, of the 16 cases 14 had received irradiation, and in 15 cases the dorsal region was involved. In Paracchi and Pricolo's series, of the three cases of carcinoma of the uterus, all developed zoster in the lumbar area, and all had been treated by irradiation.

II. Side.-There is some preponderance of involvement by the zoster on the side of the malignant lesion. Even

\begin{tabular}{|c|c|c|c|c|}
\hline & Ipsilateral & Contralateral & Site not Specified & Total \\
\hline 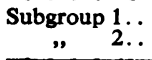 & $\begin{array}{l}7 \\
5\end{array}$ & $\begin{array}{l}4 \\
3\end{array}$ & $\frac{1}{4}$ & 12 \\
\hline Total .. & 12 & 7 & 5 & 24 \\
\hline
\end{tabular}

when the cases involving the upper dorsal region are considered there is again a slight preponderance of ipsilateral involvement, as here shown. Thus if the possibility of

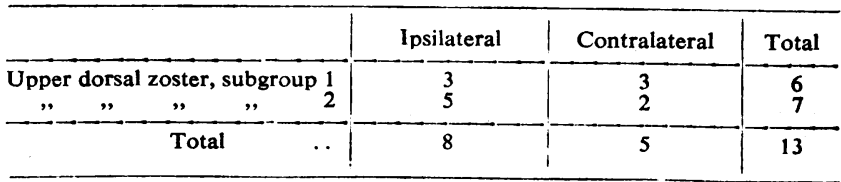

TABLE II.-Carcinoma of Breast-Subgroup 2. Twelve Cases of Carcinoma of Breast with Various Treatments

\begin{tabular}{|c|c|c|c|c|c|c|c|c|}
\hline No. & $\begin{array}{c}\text { Age } \\
\text { and Sex }\end{array}$ & Treatment & Site of Zoster & Relationship & Interval & Notes & $\begin{array}{l}\text { Follow-up } \\
\text { after Zoster }\end{array}$ & Diagnosis \\
\hline A 695 & $52 \mathrm{~F}$ & $\begin{array}{l}\text { DXR } L \text { chest } \\
\text { DXR } R \text { breast }\end{array}$ & Right V & $\begin{array}{l}\text { Contralateral } \\
\text { Ipsilateral }\end{array}$ & $16 / 12$ & Varicella same time & ISQ $24 / 12$ & Histological \\
\hline 251 & $52 \mathrm{~F}$ & DXR L chest & Right D1, 2 & Contralateral & $47 / 12$ & Effusion after 10/12 & Died $14 / 12$ meta- & Clinical \\
\hline A 352 & $72 \mathrm{~F}$ & DẌR LSC" & $?$ & "? & $\begin{array}{r}9 / 12 \\
15 / 12\end{array}$ & & $\begin{array}{l}\text { stases pleura } \\
\text { Died } 5 / 12 ? \text { cause }\end{array}$ & Histological \\
\hline 407 & $58 \mathrm{~F}$ & $\begin{array}{l}\text { DXR R chest } \\
\text { DXR RSC and axilla }\end{array}$ & Right D6 & $\begin{array}{c}\text { Ipsilateral } \\
\text { " }\end{array}$ & $\begin{array}{l}8 / 12 \\
3 / 12\end{array}$ & & $\begin{array}{l}\text { Died } 7 / 12 \text { meta- } \\
\text { stases lungs }\end{array}$ & Clinical \\
\hline C 119 & $48 \mathrm{~F}$ & DẌR L chest ạd spine & $?$ & "? & $\begin{array}{l}1 / 12 \\
6 / 12\end{array}$ & $\begin{array}{l}\text { Metastases D4 and 5, } \\
6 / 12 \text { before zoster }\end{array}$ & $\begin{array}{c}\text { Died } 8 / 12 \text { meta- } \\
\text { stases liver }\end{array}$ & Histological \\
\hline C 80 & $65 \mathrm{~F}$ & DXR R chest & Right D3, 4 & Ipsilateral & $9 / 12$ & & ISQ $10 / 12$ & " \\
\hline B 1097 & $65 \mathrm{~F}$ & DXR dorsal spine & Right D11 & 一 & $2 / 12$ & DXR for Paget's dis- & NSR 21/12 & Clinical \\
\hline 35 & $46 \mathrm{~F}$ & DXR pelvis & Left $C 2,3$ & - & $20 / 12$ & Contact $1 / 12$ later & ISQ 40/12 & $"$ \\
\hline 042 & $46 \mathrm{~F}$ & Excision and radium $L$ & Left D2, 3 & Ipsilateral & $144 / 12$ & $\begin{array}{l}\text { Metastases spine } \\
24 / 12 \text { before zoster }\end{array}$ & ISQ $4 / 12$ & Histological \\
\hline 185 & $48 \mathrm{~F}$ & $\begin{array}{l}\text { DXR L chest } \\
\text { DXR spine } \\
\text { DXR ribs } \\
\text { Excision and radium } L \\
\text { breast }\end{array}$ & Left D3-6 & Ipsilateral & $\begin{array}{l}84 / 12 \\
24 / 12 \\
12 / 12 \\
28 / 12\end{array}$ & - & ISQ $48 / 12$ & " \\
\hline O 192 & $64 F$ & $\begin{array}{l}\text { DXR L axilla } \\
\text { DXR L breast } \\
\text { D艹XR LSC" }\end{array}$ & Right D (upper) & Contralateral & $\begin{array}{r}12 / 12 \\
44 / 12 \\
8 / 12 \\
3 / 12\end{array}$ & & $\underset{\text { Dtases lungs }}{\text { Died } 1 / 12 \text { meta- }}$ & Clinical \\
\hline D 795 & $65 \mathrm{~F}$ & $\begin{array}{l}\text { DXR } \mathbf{R} \text { breast } \\
\text { DX } \mathbf{R} \text { chest }\end{array}$ & Right D1, 2 & $\begin{array}{c}\text { Ipsiläteral } \\
\text { ", }\end{array}$ & $\begin{array}{l}5 / 12 \\
9 / 12 \\
6 / 12\end{array}$ & & ISQ $1 / 12$ & Histological \\
\hline
\end{tabular}

DXR $=$ Deep $x$-ray therapy. ISQ $=$ In statu quo. NSR $=$ No signs of recurrence. LSC $=$ Left supraclavicular fossa. RSC $=$ Right supraclavicular fossa. 
metastatic involvement of the spinal roots is negatived by consideration of the follow-up notes and also by the absence of any other clinical symptoms, then the effect of $x$ rays on the root ganglia or on the skin of the opposite side must be considered to account for contralateral involvement. It has already been pointed out that the spinal roots of both sides at the level of D1-3 may be included in the field of irradiation in the post-operative breast-irradiation technique, and in addition the skin of the contralateral chest wall supplied by spinal roots D2-6 (approximately).

In this connexion Pendergrass observes that nine of the cases of zoster were on the same side as the neoplasm of the breast and three were on the opposite side.

III. Interval Between Zoster and Previous Irradiation.The time interval between the last irradiation and the onset of zoster was :-subgroup $1: 3,3,3,4,6,8$, $9,10,12,13,13$, and 16 months; subgroup 2 : $1,2,3,6,6,9,9,11,12,12,15$, and 20 months. It will be seen that 19 of the 24 cases developed zoster within 12 months of irradiation, and that the peak incidence is from three to nine months. This observation is even more marked when the latent intervals in the cases of upper dorsal zoster only are examined. The figures for the 13 cases in this combined group are $1,3,3,3,3,4,6,6,9,9,10,12$, and 12 months. It is noteworthy that all 13 cases occurred within 12 months of irradiation.

Pendergrass notes that in his series of zoster cases the incidence was from 5 to 36 months after treatment for carcinoma of the breast (none before five months). Craver notes for seven cases of zoster after irradiation in reticulosis latent intervals of $1,3,6,7,9,18$, and 36 months after treatment. Paracchi and Pricolo note for five cases of zoster after irradiation in cancer and reticulosis latent intervals of $2,3,5,21$, and 48 months respectively. Greenfield and Stark, in three cases of irradiation neuropathy following seminoma testis, note latent intervals of three to five months.
For the malignant (other than breast) cases described later the latent intervals were $1,2,3,4,5,5,5,5,6,8$, $10,18,18,43$, and 60 months and for the non-malignant group described later $6,6,8,11,26$, and 36 months after irradiation.

When all groups are added together the distribution is as follows :

Zoster Development

\begin{tabular}{l|l|l|l|l|l|l|l|l|l|l|l|l|l|l|l|l|}
\hline Months after treatment : & 1 & 2 & 3 & 4 & 5 & 6 & 7 & 8 & 9 & 10 & 11 & 12 & $13-24$ & $25-36$ & $36+$ \\
\hline No. of cases $\ldots$ &. & 3 & 3 & 7 & 2 & 5 & 7 & 1 & 3 & 4 & 2 & 2 & 3 & 9 & 3 & 3
\end{tabular}

The peak incidence in 57 cases of zoster after irradiation is seen to be at three to nine months (see Fig. 2). These figures apply to the time interval from the last treatment. In 16 instances previous irradiation was given, and in the

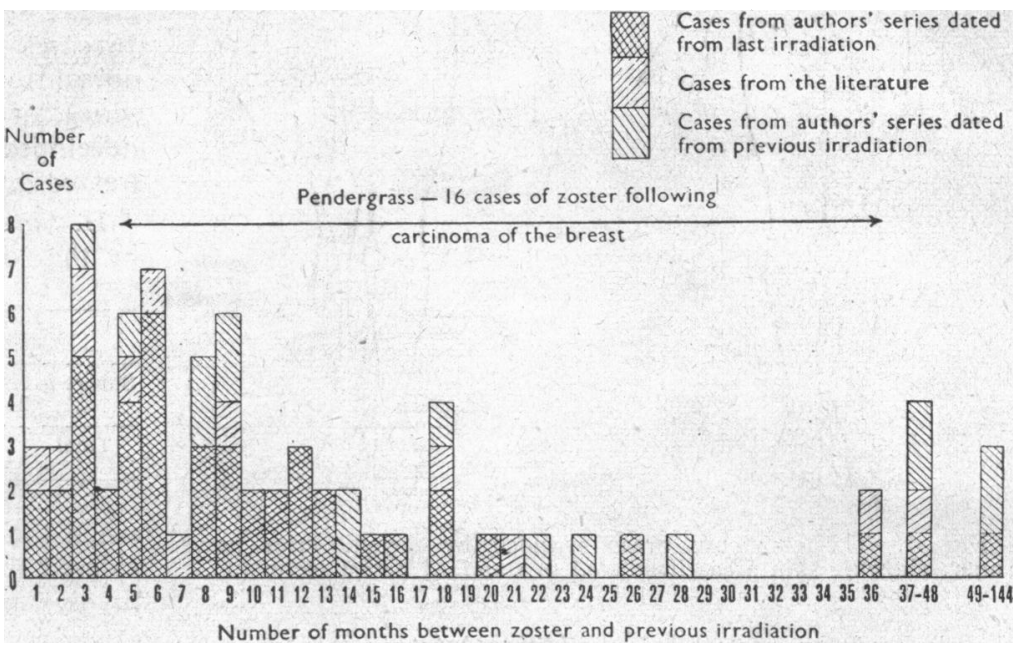

FIG. 2.-The time interval between incidence of zoster and previous irradiation.

graph the time interval from these treatments is shown separately.

IV. Follow-up History.-(1) Subgroup 1 :- In no case was there clinical evidence of spinal involvement either

TABLE III.-Fifteen Cases of Various Malignant Diseases Treated by Irradiation

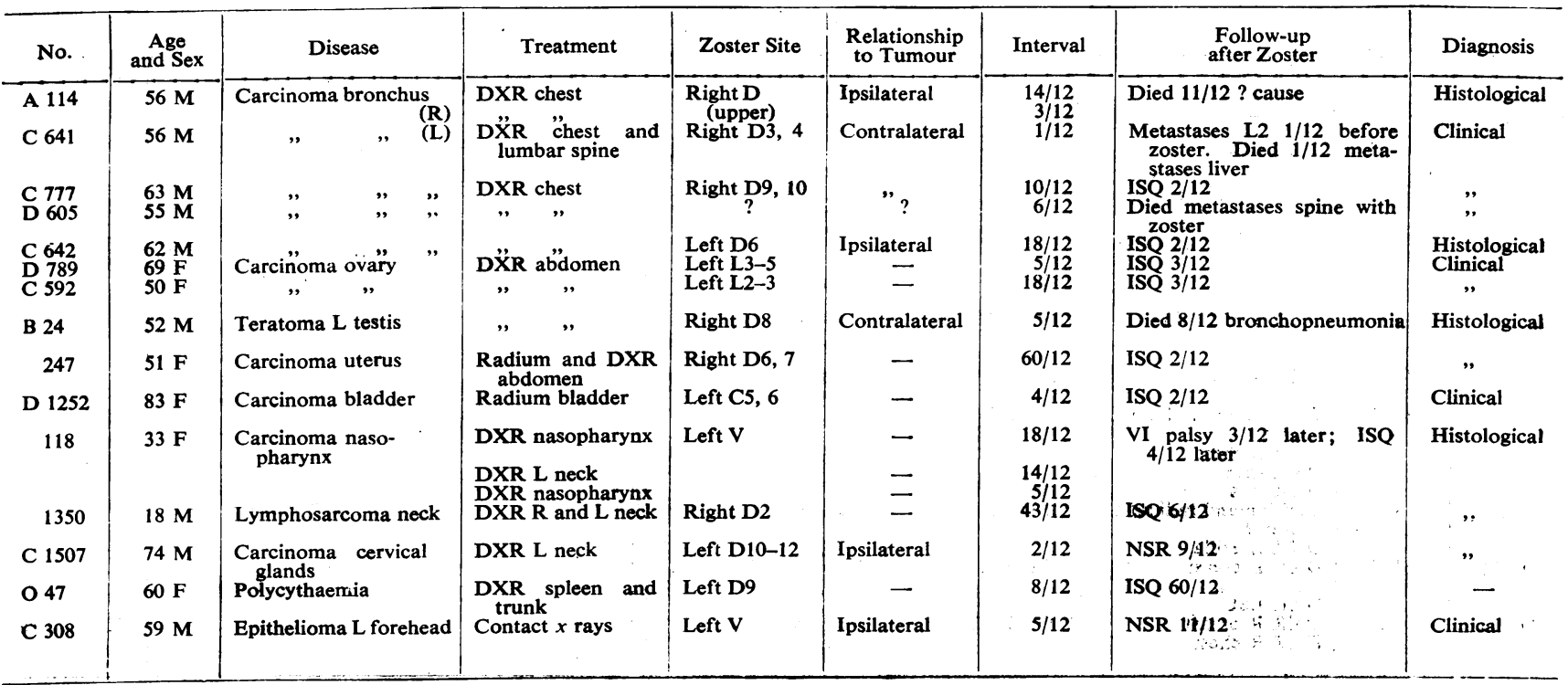


before or after the zoster. Eight cases showed no signs of recurrence of the disease at intervals of $7,9,9,10,11$, 16,25 , and 30 months after zoster (equivalent to $12,17,17$, $20,26,28,33$, and 38 months after irradiation). One case developed metastases in the femur 26 months after zoster. One patient died 11 months after zoster with liver metastases. Two cases have no current follow-up record. (2) Subgroup 2:-Two cases had radiological evidence of spinal metastases, one six months and the other two years before the development of zoster. In the first case the site of the zoster has not been established, and nor could it be correlated in the second case, in which bone metastases were multiple. In the remaining 10 cases there is no evidence of spinal metastases before or after the zoster, although four patients died of metastases $1,5,7$, and 14 months after the zoster. The remaining six patients are still alive $1,10,21$, 24,40 , and 48 months after zoster (equivalent to $7,19,23$, 35,60 , and 60 months after irradiation).

\section{Malignant (Other than Breast) and Non-Malignant Cases}

The 15 cases of malignant disease (Table III) vary in character and include five cases of carcinoma of the bronchus, two of carcinoma of the ovary, and one case each of lymphosarcoma of the neck, lympho-epithelioma of the nasopharynx, teratoma testis, carcinoma of the cervix, carcinoma of the bladder, secondary malignant glands of the neck, epithelioma of the forehead, and polycythaemia.

The six cases of the non-malignant group (Table IV) consist of two cases of spondylitis, two of osteoarthritis, one of syringomyelia, and one of tuberculous adenitis of the neck. Both groups are analysed together for simplicity.

I. Site

\begin{tabular}{|c|c|c|c|c|c|c|c|}
\hline & $\begin{array}{l}\text { Fifth } \\
\text { Nerve }\end{array}$ & Cervical & $\begin{array}{l}\text { Upper } \\
\text { Dorsal }\end{array}$ & $\begin{array}{l}\text { Lower } \\
\text { Dorsal }\end{array}$ & Lumbar & $\begin{array}{l}\text { Not } \\
\text { Spec. }\end{array}$ & Total \\
\hline $\begin{array}{l}\text { Malignant .. } \\
\text { Non-malignant }\end{array}$ & $\underline{2}$ & $\begin{array}{l}1 \\
1\end{array}$ & $\stackrel{4}{-}$ & $\begin{array}{l}5 \\
3\end{array}$ & $\begin{array}{l}2 \\
1\end{array}$ & $\begin{array}{l}1 \\
1\end{array}$ & $\begin{array}{r}15 \\
6\end{array}$ \\
\hline Total & 2 & 2 & 4 & 8 & 3 & 2 & 21 \\
\hline
\end{tabular}

The lower dorsal region shows the maximum incidence. II. Side

\begin{tabular}{ll|c|c|c|c} 
& & Ipsilateral & Contralateral & Unspecified & Total \\
\hline Malignant .. & $\ldots$ & 4 & 3 & 8 & 15 \\
Non-malignant & $\cdots$ & - & - & 6 & 6 \\
\hline
\end{tabular}

III. The interval between zoster and previous irradiation has been discussed under " carcinoma of the breast," above.

IV. Follow-up History.-In the malignant (other than breast) group there is evidence of spinal involvement concurrently with the zoster in one case and spinal involvement one month before the zoster in a second case. In the latter case, metastases involved L2 and the zoster involved the upper dorsal region at the level of which the patient had received deep $x$ ray therapy. In the residual 13 cases there is no evidence of spinal metastases before or after the zoster, although two of these patients died at intervals of 8 and 11 months after the zoster. The 11 remaining cases were alive at intervals of $2,2,2,2,3,3$, $4,6,9,11$, and 60 months after the zoster (equivalent to 6 , $8,9,11,12,16,20,21,49,62$, and 68 months after the last irradiation). The case of the nasopharyngeal tumour with fifth-nerve zoster developed sixth-nerve palsy three months after zoster, suggesting an infiltrative basis for the zoster.
TABLE IV.-Six Cases of Non-malignant Disease Treated by Irradiation

\begin{tabular}{|c|c|c|c|c|c|c|}
\hline No. & $\begin{array}{l}\text { Age } \\
\text { and } \\
\text { Sex }\end{array}$ & Disease & Treatment & $\begin{array}{l}\text { Site of } \\
\text { Zoster }\end{array}$ & Interval & Follow-up \\
\hline A 972 & $25 \mathrm{~F}$ & Spondylitis & DXR spine & Right C5, 6 & $26 / 12$ & ISQ $8 / 12$ \\
\hline 1258 & $27 M$ & $" \quad "$ & " " " & Right D10 & $\begin{array}{l}9 / 12 \\
6 / 12\end{array}$ & $\begin{array}{l}\text { ISQ 36/12 } \\
\text { (Bell's palsy } \\
6 / 12 \text { before }\end{array}$ \\
\hline 298 & $43 \mathrm{~F}$ & Syringo- & DXR cervi- & Left D9 & $36 / 12$ & ISQ 24/12 \\
\hline A 421 & $43 \mathrm{~F}$ & Tb adenitis & DXR L neck & D6-9 & $22 / 12$ & ISQ $7 / 12$ \\
\hline C 291 & $73 \mathrm{~F}$ & $\begin{array}{l}\text { neck } \\
\text { Sacro-ileitis }\end{array}$ & DẌR lower & ? & $\begin{array}{r}11 / 12 \\
6 / 12\end{array}$ & ISQ $11 / 12$ \\
\hline B 307 & $62 \mathrm{~F}$ & O.A. knees & $\begin{array}{l}\text { spR both } \\
\text { knees }\end{array}$ & Left L5, S1 & $8 / 12$ & ISQ $10 / 12$ \\
\hline
\end{tabular}

\section{Conclusions}

The analysis of our cases shows : maximal incidence of zoster at the somatic level of the neoplasm, and thus of the site of irradiation; involvement by the zoster of either the same or, to a lesser extent, the side of the body opposite to that irradiated; a maximal incidence of zoster at between three and six months following the treatment, with a gradually diminishing incidence up to two years ; and no evidence of malignant involvement of the posteriornerve root within the period of observation except possibly in four cases with vertebral involvement.

The first question to be considered is whether the irradiation may be implicated as a factor in the aetiology of zoster in these cases. We consider that the time relationship between the development of the zoster and the previous irradiation, as shown in Fig. 2, provides strong evidence that this is the case. There is some interest in the fact that late irradiation reactions in all parts of the body, associated with the relative ischaemia and fibrosis which follow endothelial proliferation, usually tend to develop at an interval of three to six months after treatment. A delayed vascular deficiency and gliosis in the spinal root ganglion or delayed fibrosis in the skin with involvement of the nerve endings might cause activation of a latent zoster virus.

The second question to be considered is the way in which the irradiation may possibly be concerned in the aetiology of herpes. In this connexion we may note (especially by consideration of the breast cancer series, where the disease is primarily unilateral that: (1) The incidence of zoster in a minority of cases is on the opposite side to that treated. (2) The level of zoster in a minority of cases does not correspond with the somatic level treated. (These two findings correspond with those of Pendergrass.) (3) One or two of the upper dorsal posterior root ganglia, on both sides, are sometimes directly irradiated in the routine technique for irradiation in carcinoma of the breast. Even when this is so, the zoster does not necessarily correspond in level with the posterior root ganglia irradiated. (4) The skin area (and thus the cutaneous nerves also) corresponding to the level involved by zoster later has in the majority of cases been irradiated. The technique of treatment often includes a portion of the skin on the opposite side of the midline anteriorly.

In view of our first conclusion and these observed facts, it would seem that zoster may result either from a systemic mechanism following the release of substances set free by irradiation, or possibly from an effect at the level of the cord concerned, through the afferent nerves of the irradiated area. No further speculation is justified, unless in all cases a correlation were established between the site or nerve tissue irradiated and the subsequent site of zoster. (The 
necessary details for such correlation were not available in our cases, the provision of the necessary minutiae in the usual treatment notes being impracticable as a routine.)

The relative rarity of zoster in patients treated with $x$ rays, even when the region of the spine is directly treated, suggests that patients vary in their sensitivity either according to the degree of fibrous reaction or according to the presence of the dormant virus. Even in a large group of cases of carcinoma of the breast treated by a similar post-operative technique the percentage developing zoster is small. A factor that may be important is that of immunity conferred by a previous attack of zoster or varicella. On the other hand, zoster developing after a prolonged period after irradiation-e.g., more than 24 months later-is likely to be purely coincidental.

Previous attempts to correlate zoster with cancer or reticulosis have been based on the hypothesis that the zoster was due to infiltration by the underlying disease of the spinal ganglia or other parts of the afferent nervous reflex arc. No other authors seem to have correlated the incidence of zoster with the administration of $x$-ray treatment in a large series where such infiltration was absent.

\section{Summary}

A series of 45 cases of zoster developing after irradiation is described.

The literature concerning the connexion between zoster on the one hand and malignant disease and reticulosis on the other is reviewed. Evidence is adduced to suggest that irradiation is implicated in the development of zoster in the majority of the cases described.

\section{REFFRENCES}

Baldridge, C. W., and Awe, C. D. (1930). Arch. intern. Med., 45, 161

Carrière (1895). Ann. Derm. Syph., Paris, 6, 892.

Charcot and Cotard (1865). Seances Mém. Soc. Biol., 4.s., 2, 41. Craver, L. F., and Haagensen, C. D. (1932). Amer. J. Cancer, 16, 502.

Epstein, E., and McEachern, K. (1937). Arch. intern. Med., 60, 867

Greenfield, M. M., and Stark, F. M. (1948). Amer. J. Roentgenol., 60, 617 .

Hall, J. N. (1923). Ibid., 10, 182.

Halle, H. (1930). Arch. Derm. Syph., Wien, 159, 238.

Head, H., and Campbell, A. W. (1900). Brain, 23, 353.

Janzen, A. H., and Warren, S. (1942). Radiology, 38, 333.

Kamman, G. R. (1928). J. A mer. med. Ass., 91, 320.

Klauder, J. V. (1947). Ibid.. 134, 245.

Mogilnitzky, B. N., and Podljaschuk, L. D. (1929). Fortschr. Röntgenstr., 40, 1096.

_ - (1930). Ibid., 41, 66.

Pancoast, H. K., and Pendergrass, E. P. (1924). Amer. J. med. Sci., 168, 326 .

Paracchi, P., and Pricolo, V. (1943). Tumori, 17, 171.

Pendergrass, E. P., and Kirsh, D. (1948). Radiology, 51, 767.

Schreus, H. T. (1926). Derm. Wschr., 83, 1606.

Sequeira, J. H., Ingram, J. T., and Brain, R. T. (1947). Disease of the Skin, Sth ed. Churchill, London.

Warren, S. (1943). Arch. Path., 35, 121.

Wohlwill, F. (1924). Fortschr. ges. Neurol. Psychiat., 89, 171.

According to the specification for stretchers recently published by the British Standards Institution the overall length of stretchers should be $7 \mathrm{ft}$. 9 in., though these requirements need not interfere with the use of $6-\mathrm{ft}$. stretchers to meet special needs, since the shorter stretchers can still be carried in ambulances designed to take those of full length. The institution recommends that stretchers should be held in position in ambulances by straps provided with buckles instead of by special locking devices, which are not universally applicable. Stretcher carriers and trolleys have also been specified. The British Standards Institution is a non-profit-making organization which was founded in 1901 and incorporated by Royal Charter in 1929. Its principal objects are to improve and simplify production and distribution. Organizations that cooperate with it include the Medical Research Council, various trade associations, and some of the Ministries. The B.M.A. is represented on the committee which prepared the standard for stretchers.

\section{MALE SUBFERTILITY INTERIM REPORT OF 3,182 CASES}

BY

\author{
H. A. DAVIDSON, M.R.C.S., L.R.C.P. \\ Clinical Pathologist, Family Planning Association
}

This report contains a survey of the findings of an investigation into male subfertility carried out at the laboratories of the Family Planning Association over a period of four years. Nothing essentially new is presented, but the general information provided by a comparatively large amount of material may be of interest.

\section{Material}

Altogether 3,182 men were examined, with a total of 5,400 semen analyses. The patients were referred by hospitals, subfertility clinics, private consultants, and general practitioners. Most of them are the husbands of wives who had failed to conceive over an average period of about two years. In many cases the wives had been examined first and no gross subfertility factor had been found. In over 800 of these the initial post-coital examination was made in this laboratory and an unsatisfactory result was found. In over 180 cases conception had occurred in the past but had terminated in early spontaneous abortion. Thus it is obvious that the material is selected. The findings in a separate group of 15 normally fertile men are included in this report.

\section{Methods}

The technique of semen examination corresponds in almost every detail to that described by Harvey and Jackson (1945). A brief recapitulation of these methods may be helpful.

Collection of Seminal Specimens.-After a minimum period of abstinence of three to four days the specimen is produced direct into a clean thin-walled glass container previously warmed to body temperature by the hand or axilla. The specimen tube is closed with a paraffinimpregnated cork, wrapped in cellulose wadding, and brought to the laboratory as soon as possible. The maximum delay allowed is two hours, and the age of most specimens in this series was well below this. About onethird of the patients produce their specimens at the laboratory. Condom specimens are not accepted except for confirmatory tests in cases of total azoospermia or extreme oligozoospermia. Fresh specimens are allowed 20 to 30 minutes for liquefaction.

\section{Semen Analysis}

On receipt of the specimen the volume is measured and a note made of its consistence.

Density, Basic Motility, Viability.-A “ bulk" dilution is prepared by adding $0.5 \mathrm{ml}$. of semen to the required amount of a buffered glucose solution at $37^{\circ} \mathrm{C}$. The dilution and all pipettes and slides are kept in the incubator at body temperature. After one hour's incubation a drop of diluted semen is placed on a Thoma-Zeiss haemocytometer slide and allowed to sediment for five minutes. The count is done in two stages: (1) immotile and sluggish spérmatozoa are counted, active ones are disregarded; and (2) all spermatozoa are immobilized by brief application of heat to the cover-slip and counted after further sedimentation. (This is a modification of Harvey and Jackson's technique, in which the two stages of counting are done on separate haemocytometer slides: on one of them the spermatozoa are immobilized immediately by exposure to osmic acid vapour. Repeated cross-checking has shown that these 